\title{
CLINICAL VERSUS LIGHT'S CRITERIA VERSUS SERUM PLEURAL FLUID ALBUMIN GRADIENT IN DIFFERENTIATING BETWEEN TRANSUDATIVE AND EXUDATIVE PLEURAL EFFUSIONS
}

\author{
Pandu Viritha1 ${ }^{1}$ Ramya Gadam², V. Venkata Ramana Reddy3
}

${ }_{1}^{1}$ Assistant Professor, Department of Pulmonary Medicine, Maharaja Institute of Medical Sciences, Nellimarla, Andhra Pradesh, India. ${ }^{2}$ Postgraduate Student, Department of Pulmonary Medicine, Maharaja Institute of Medical Sciences, Nellimarla, Andhra Pradesh, India.

${ }^{3}$ Professor and HOD, Department of Pulmonary Medicine, Maharajah Institute of Medical Sciences, Nellimarla, Andhra Pradesh, India.

\section{BACKGROUND} ABSTRACT

The first and important step is to classify pleural effusion into transudates and exudates. Traditionally, Light's criteria are used to separate transudative from exudative pleural effusions. Light's criteria misidentify about $20 \%$ of transudates as exudates, particularly in patients with heart failure on diuretics. In such cases serum pleural fluid albumin gradient is used to correctly identify transudates. Apart from Light's criteria, the nature of the effusion can also be assessed by clinical examination. Very few studies have been done to evaluate the efficacy of clinical judgement with respect to Light's criteria in determining the transudative or exudative nature of the pleural effusion.1,2 Few studies have been done to evaluate the efficacy of Light's criteria and serum pleural fluid albumin in determining transudative and exudative pleural effusions. ${ }^{3,4}$ But no studies were done to evaluate the efficacy of clinical judgement, Light's criteria and serum pleural fluid albumin gradient in differentiating transudative and exudative pleural effusions.

\section{MATERIALS AND METHODS}

The observational, descriptive, cross-sectional study was conducted on 60 patients coming to the outpatient department as well as those admitted to the wards in Department of Pulmonary Medicine, Maharajah Institute of Medical Sciences during the period November 2013 to October 2015 with evidence of pleural effusion. Pleural fluid analysis is done to differentiate between transudative and exudative effusions, additionally Light's criteria and serum pleural fluid albumin gradient is used for all samples.

\section{RESULTS}

Of the 60 patients, 50 were males and 10 were females. The age of the patients ranged between 15 - 85 years. Of the 60 effusions, $20(33.3 \%)$ are transudates and $40(66.6 \%)$ are exudates. Among the transudates CHF was the commonest disease and among exudates tuberculosis was the leading disease followed by synpneumonic effusion. Transudates were common in older age group, whereas exudates were common in younger and middle age group. Of 20 transudative effusions, clinical presumption could rightly classify all of them as transudates. Light's criteria could classify only 12 of them as transudates and it misclassified 8 cases, of which ( 6 cases of CHF, 1 case of CKD, 1 case of Cirrhosis) on diuretic as exudates. SAPA could rightly classify all of them as transudates. Out of the 40 exudative effusions, clinical presumption could rightly classify 39 effusions, but misclassified 1 case of CHF as transudate. Light's criteria could rightly classify all the 40 exudative effusions as exudates. SAPA could rightly classify 39 effusions, but misclassified 1 case of synpneumonic effusion as transudate.

\section{CONCLUSION}

The present study shows that the clinical criteria and SAPA are superior to Light's criteria in identifying the transudative effusions $(100 \%$ vs $60 \%$ vs $100 \%)$. Light's criteria identified exudative effusions better than clinical criteria and SAPA $100 \%$ vs $97.5 \%$ vs 97.5\%). So, in primary health centres where biochemical analysis is not available, clinical criteria can be used to separate transudates and exudates.

\section{KEY WORDS}

Transudates, Exudates, Clinical Diagnosis, Light's Criteria, Serum Pleural Fluid Albumin Gradient, CHF, Cirrhosis, TB, Synpneumonic Effusion.

HOW TO CITE THIS ARTICLE: Viritha P, Gadam R, Reddy VVR. Clinical versus Light's criteria versus serum pleural fluid albumin gradient in differentiating between transudative and exudative pleural effusions. J. Evolution Med. Dent. Sci. 2018;7(45):48884892, DOI: $10.14260 /$ jemds/2018/1088

'Financial or Other Competing Interest': None.

Submission 29-09-2018, Peer Review 22-10-2018,

Acceptance 29-10-2018, Published 05-11-2018.

Corresponding Author:

Dr. Pandu Viritha,

Door No. 3-52, Netaji Nagar,

Old Dairy Farm,

Visakhapatnam-530040,

Andhra Pradesh, India.

E-mail: viritha_doc@yahoo.co.in

DOI: $10.14260 /$ jemds $/ 2018 / 1088$

\section{BACKGROUND}

The first and important step is to classify pleural effusion into transudates and exudates. Traditionally, Light's criteria is used to separate transudative from exudative pleural effusions. Light's criteria misidentify about $20 \%$ of transudates as exudates, particularly in patients with heart failure on diuretics. In such cases, serum pleural fluid albumin gradient is used to correctly identify transudates. The primary reason to separate transudative from exudative pleural effusion is that if a patient has transudative pleural effusion, systemic condition can be treated with the expectation that effusion will resolve. 
Apart from Light's criteria, the nature of the effusion can also be assessed by clinical examination symptomatology and all available information including Chest X-ray, ECG, 2D-Echo, USG abdomen, blood and serum biochemistry etc. If clinical presumption can accurately identify the transudates and exudates, the cost and morbidity associated with diagnostic thoracentesis can be avoided.

Very few studies were done to evaluate the efficacy of clinical judgement with respect to Light's criteria in determining the transudative or exudative nature of the pleural effusion.1,2 Few studies were done to evaluate the efficacy of Light's criteria and Serum pleural fluid albumin in determining transudative and exudative pleural effusions.3,4 But no studies were done to evaluate the efficacy of clinical judgement, Light's criteria and serum pleural fluid albumin gradient in differentiating transudative and exudative pleural effusions.

\section{Objectives}

To assess the ability of clinical versus Light's criteria versus serum pleural fluid albumin gradient in differentiating between transudative and exudative pleural effusions.

\section{MATERIALS AND METHODS}

The observational, descriptive, cross-sectional study was conducted on 60 patients coming to the outpatient department as well as those admitted to the wards in Department of Pulmonary Medicine, Maharajah Institute of Medical Sciences during the period from November 2013 to October 2015 with evidence of pleural effusion. In this study, 60 consecutive patients with evidence of pleural effusion on chest radiographs were screened.

The patients who are seropositive for HIV and having any bleeding diathesis are excluded from the study.

All the 60 patients in the study met the inclusion criteria. Written informed consent was obtained from each study subject. Detailed history was taken, thorough clinical examination was done including CXR and clinical diagnosis was formed and then lab data like CBP, Blood and Urine biochemistry were obtained. After these each patient was subjected to diagnostic thoracentesis. ECG, 2D-Echo, USG abdomen and LFT were done in relevant cases.

\section{All the Patients Selected were Subjected to the following Investigations}

1. Sputum examination for M. Tuberculosis by direct smear for AFB on 2 consecutive days.

2. X-ray chest, PA view.

3. Serology for Human immunodeficiency virus.

4. Pleural fluid analysed for total count, differential count, smear and culture for AFB, total protein, glucose and albumin levels, ADA levels, Gram staining and culture and sensitivity, malignant cytology by smear and cell block.

5. Pleural biopsy using Abrams pleural biopsy needle.

6. Serum protein and albumin were also sent.

7. Bronchial washings for malignant cytology and transbronchial biopsy, CECT thorax, FNAC of Lymph node (selected cases).

8. ECG, 2D-echo, USG-Abdomen, renal profile, LFT (in selected cases).

9. The following biochemical parameters were estimated and calculated: (1) The criteria of Light et al (namely pleural fluid/ serum protein ratio, pleural fluid/ serum LDH ratio, pleural fluid LDH concentration). In this study pleural fluid/ serum protein ratio alone is considered as according to Light's criteria exudates can meet any one of the criteria. (2) Albumin gradient (Serum albumin concentration minus pleural effusion albumin concentration). The clinical presumption of the nature of the effusion (Transudate or Exudate) was based on all available information obtained before performing thoracentesis and was compared with that obtained from biochemical criteria.

\section{Diagnostic Thoracentesis}

A diagnostic thoracentesis is performed on every patient of pleural effusion with the fluid thickness of more than $10 \mathrm{~mm}$ on decubitus chest radiograph.

\section{Technique}

Once the site for the thoracentesis is identified, the skin surrounding the site is cleaned thoroughly with an antiseptic solution. Then local anaesthesia is given with $2 \%$ xylocaine to skin, subcutaneous tissue, muscles and parietal pleura. Then 20 cc syringe with $22-\mathrm{G}$ needle is introduced through the intercostal space at the upper border of lower rib and 10 - 20 cc of pleural fluid is aspirated.

\section{Complications}

Vasovagal shock, pneumothorax, infections of the pleural space, haemothorax, chest pain and cough.

\section{Statistical Methods}

As the study is a descriptive study here, categorical data is represented as proportions and quantitative data as mean and standard deviations and data will be analysed using excel sheets. This data is used to calculate sensitivity, PPV and accuracy.

\section{RESULTS}

A total of 60 patients were evaluated. After necessary diagnostic workup, the effusions were definitively classified as transudates in 20 patients (33.3\%) and as exudates in 40 patients $(66.6 \%)$.

\begin{tabular}{|c|c|c|c|}
\hline \multicolumn{2}{|c|}{ Transudates } & Exudates \\
\hline CHF & 14 & TB & 18 \\
\hline Cirrhosis & 01 & Malignancy & 04 \\
\hline $\begin{array}{c}\text { Anaemia and } \\
\text { Hypoproteinaemia }\end{array}$ & 01 & Synpneumonic Effusion & 14 \\
\hline CKD & 04 & Pancreatic Effusion & 02 \\
\hline & & Rheumatoid Effusion & 01 \\
\hline & \multicolumn{2}{|c|}{ Table 1 } & 01 \\
\hline Total & $\begin{array}{c}\mathbf{2 0} \\
(\mathbf{3 3 . 3 \% )}\end{array}$ & $\begin{array}{c}\mathbf{4 0} \\
\mathbf{6 6 6 . 6 \% )}\end{array}$ \\
\hline \multicolumn{4}{|c|}{ Total } \\
\hline
\end{tabular}

\section{Transudative Effusion}

CHF is by far the commonest transudative effusion (70\%) in our study. TB (45\%) and synpneumonic effusion (35\%) together accounted $80 \%$ of exudative effusion in our study of 20 transudative effusions, clinical presumption could rightly classify all of them as transudates. Light's criteria could classify only 12 of them as transudates and it misclassified 8 cases, of which (6 cases of CHF, 1 case of CKD, one case of Cirrhosis) on diuretic as exudates. Serum pleural fluid albumin gradient could rightly classify all of them as transudates. 


\begin{tabular}{|c|c|c|c|c|c|c|c|}
\hline Final Diagnosis & & Clinical Presumption & & Light's Criteria & & SAPA & CHF \\
\hline CHF & 14 & CHF & 15 & CHF & 08 & 14 \\
\hline Cirrhosis & 01 & Cirrhosis & 01 & Cirrhosis & 00 & Cirrhosis & 01 \\
\hline $\begin{array}{c}\text { Anaemia and } \\
\text { Hypoproteinaemia }\end{array}$ & 01 & $\begin{array}{c}\text { Anaemia and } \\
\text { Hypoproteinaemia }\end{array}$ & 01 & $\begin{array}{c}\text { Anaemia and } \\
\text { Hypoproteinaemia }\end{array}$ & 01 & $\begin{array}{c}\text { Anaemia and } \\
\text { Hypoproteinaemia }\end{array}$ & 01 \\
\hline CKD & 04 & CKD & 04 & CKD & 03 & CKD & 04 \\
\hline Total & $\mathbf{2 0}$ & \multicolumn{2}{|c|}{ Table $\mathbf{2}$} & Tynpneumonic & 01 \\
\hline \multicolumn{7}{|r|}{} \\
\hline
\end{tabular}

\section{Exudative Effusion}

Out of the 40 exudative effusions clinical presumption could rightly classify 39 effusions, but misclassified 1 case of CHF as transudate. Light's criteria could rightly classify all the 40 exudative effusions as exudates. Serum pleural fluid albumin gradient could rightly classify 39 effusions, but misclassified 1 case of synpneumonic effusion as transudate.

\begin{tabular}{|c|c|c|c|c|c|c|c|}
\hline Final Diagnosis & & $\begin{array}{c}\text { Clinical } \\
\text { Presumption }\end{array}$ & & Light's Criteria & & SAPA & \\
\hline TB & 18 & $\mathrm{~TB}$ & 18 & TB & 18 & TB & 18 \\
\hline Malignancy & 04 & Malignancy & 04 & Malignancy & 04 & Malignancy & 04 \\
\hline Synpneumonic Effusion & 14 & Synpneumonic Effusion & 14 & $\begin{array}{c}\text { Synpneumonic } \\
\text { Effusion }\end{array}$ & 14 & Synpneumonic Effusion & 13 \\
\hline Pancreatic Effusion & 02 & Pancreatic Effusion & 02 & Pancreatic Effusion & 02 & Pancreatic Effusion & 02 \\
\hline Rheumatoid Effusion & 01 & Rheumatoid Effusion & 01 & Rheumatoid Effusion & 01 & Rheumatoid Effusion & 01 \\
\hline \multirow[t]{3}{*}{ CHF } & 01 & CHF & & CHF & 07 & CHF & 01 \\
\hline & & & & Cirrhosis & 01 & & \\
\hline & & & & CKD & 01 & & \\
\hline Total & 40 & Total & 39 & Total & 48 & Total & 39 \\
\hline
\end{tabular}

\begin{tabular}{|c|c|c|}
\hline Clinically Transudate & Clinically Exudate & Final Diagnosis \\
\hline $20(\mathrm{TP})$ & $0(\mathrm{FN})$ & 40 \\
\hline $01(\mathrm{FN})$ & $39(\mathrm{TP})$ & 60 \\
\hline 21 & 39 & \\
\hline \multicolumn{2}{|c|}{ Table 4. Sensitivity, PPV and Accuracy of Clinical Criteria } \\
\hline
\end{tabular}

Sensitivity for Transudates: $20 / 20 * 100=100 \%$

Sensitivity for Exudates: $39 / 40 * 100=97.5 \%$

PPV (Positive Predictive Value) for transudates: $20 / 21 * 100=95.2 \%$

PPV (Positive Predictive Value) for Exudates: 39/39*100 = 100\%

Accuracy of Clinical Criteria: 59/60* $100=98.3 \%$

\begin{tabular}{|c|c|c|}
\hline Light's Transudate & Light's Exudate & Final Diagnosis \\
\hline $12(\mathrm{TP})$ & $08(\mathrm{FN})$ & 40 \\
\hline $0(\mathrm{FN})$ & $40(\mathrm{TP})$ & 60 \\
\hline 12 & 48 & \\
\hline \multicolumn{2}{|c|}{ Table 5. Sensitivity, PPV and Accuracy of Light's Criteria } \\
\hline
\end{tabular}

Sensitivity for Transudates: $12 / 20 * 100=60 \%$

Sensitivity for Exudates: $40 / 40 * 100=100 \%$

PPV (Positive Predictive Value) for transudates: $12 / 12 * 100=100 \%$

PPV (Positive Predictive Value) for exudates: 40/48*100 $=88.30 \%$

Accuracy of Light's Criteria: $52 / 60 * 100=86.6 \%$

\begin{tabular}{|c|c|c|}
\hline SAPA Transudate & SAPA Exudate & Final Diagnosis \\
\hline $20(\mathrm{TP})$ & $0(\mathrm{FN})$ & 40 \\
\hline $01(\mathrm{FN})$ & $39(\mathrm{TP})$ & 60 \\
\hline 21 & 39 & \\
\hline \multicolumn{2}{|r|}{ Table 6. Sensitivity, PPV and Accuracy of SAPA } \\
\hline
\end{tabular}

Sensitivity for Transudates: $20 / 20 * 100=100 \%$

Sensitivity for Exudates: $39 / 40 * 100=97.5 \%$

PPV (Positive Predictive Value) for Transudates: 20/21 * $100=95.2 \%$

PPV (Positive Predictive Value) for Exudates: 39/39* $100=100 \%$ 
Accuracy of SAPA: $59 / 60 * 100=98.3 \%$

\section{DISCUSSION}

The first step in the diagnosis of pleural effusion is classifying them into transudates and exudates. Light's criteria are the standard for differentiating transudative and exudative pleural effusions, but main disadvantage is misclassification of $20 \%-30 \%$ of transudates which were on diuretic therapy as exudates.

In a study done by [Romero et al,1,2 Burgess et al, 5 Vives et al, Gazquez I et al] used a number of alternative criteria such as pleural fluid cholesterol levels, serum and pleural fluid albumin gradient, serum and pleural fluid protein gradient, pleural fluid and serum bilirubin ratio, cholinesterase ratio etc., which showed that Light's criteria correctly classified exudates but misclassified transudates which were on diuretic therapy as exudates which were correctly identified by SAPA. All the criteria invariably require diagnostic thoracentesis, which is associated with certain risk and expenditure.

The nature of the pleural effusion can also be assessed by clinical examination based on the symptomatology and lab data such as X-ray Chest, ECG, Blood and Urine Biochemistry, Complete Blood Picture (CBP) with the added help of USG abdomen and 2D Echo. This study is aimed at studying the utility of clinical judgement, Light's criteria and SAPA in determining the nature of pleural effusion and to determine its superiority or inferiority with respect to each other. A total of 60 patients were evaluated, of which 50 were males and 10 were females. The age of the patients ranged between 15 - 85 years. After necessary diagnostic workup, the effusions were definitively classified as transudates in 20 patients (33.3\%) and as exudates in 40 patients $(66.6 \%)$. Among the transudates, CHF was the commonest disease and among exudates tuberculosis was the leading disease followed by synpneumonic effusion. Transudates were common in older age group, whereas exudates were common in younger and middle age group.

\section{Analysis of Transudative Effusion}

Out of the 20 confirmed transudative effusions, clinical criteria could rightly classify all of them as transudates. Whereas Light's criteria could classify only 12 of them as transudates. It misclassified 8 ( 6 had CHF, 1 had CKD and 1 had cirrhosis) of them as exudates, which were on diuretic therapy. These 8 cases were proved as transudates by SAPA (Serum and pleural fluid albumin gradient). The statistical analysis of the results showed that the sensitivity for transudative pleural effusion was $60 \%$ by Light's criteria, $100 \%$ by clinical criteria and $100 \%$ by SAPA. It is because 8 out of 20 cases of transudates were misclassified as exudates, Light's criteria lost accuracy. The sensitivity levels for transudates in the present study are comparable to the $77 \%$ sensitivity of Santiago Romero and Alfredo et al study, where a large group of 297 patients were studied between 198689.1

In the present study $8 / 20(40 \%)$ of transudates were misclassified, which is close to $23 \%$ misclassified as transudates in the Santiago Romera et al study ${ }^{2}$ and 29\% misclassified as transudates in Bielsa S, Porcel JM and Castellote J et al study. ${ }^{6}$ Another study by Peterman and
Speicher who evaluated 495 patients with pleural effusions, $33 \%$ of $\mathrm{CHF}$ cases were wrongly classified as exudates. Bernard J Roth, MD; Thomas F O'Meara, MD studied 59 patients with effusions, of which 41 were exudates and 18 were transudates. Light's criteria misclassified 5 transudative effusions as exudates, whereas serum pleural fluid albumin gradient correctly classified as having transudates. ${ }^{3}$

MC Dhar, S Chaudhuri, K Basu, TJ Sau, D Paland, K Mitra studied 50 patients of which Light's criteria diagnosed all the 35 cases of exudates, but 2 cases of heart failure. 68 (Transudate) were misclassified as exudate. Using serumeffusion albumin gradient, all heart failure patients were correctly classified as having transudate. ${ }^{4}$

In the study of Burgess et $a \mathrm{l}, 5$ the gradient had a sensitivity and specificity of $87 \%$ and $92 \%$, respectively. Dr. Padmasree Dantu and Dr. Srinivas Pusuluri ${ }^{7}$ studied 50 patients with pleural effusions, of which Light's criteria correctly identified all the exudates but misdiagnosed 2 cases out of 6 transudates (cases of cardiac failure). By using albumin gradient of $1.2 \mathrm{~g} / \mathrm{dL}$ or less to indicate exudate and values more than $1.2 \mathrm{~g} / \mathrm{dL}$ to indicate transudate, all the patients (30 exudates and 20 transudates) were correctly diagnosed. Light's criteria are accurate for identifying exudates, but not so much in the case of transudates. The serum-effusion albumin gradient is accurate equally for both exudates and transudates.

In the present study 20/20 (100\%) of transudates were correctly identified as transudates by SAPA, which is close to Romero-Candeira and colleagues ${ }^{2}$ who studied 64 patients with transudative pleural effusions and reported that the Light's criteria identified $75 \%$ correctly and the serumpleural fluid albumin gradient identified $86 \%$ correctly. In Bielsa S, Porcel JM and Castellote J et al study, ${ }^{6} 107$ of 364 transudates (29\%) caused by Congestive Heart Failure (CHF) were misclassified as exudates. In these 107 instances, a serum-pleural fluid albumin gradient greater than $1.2 \mathrm{gm} / \mathrm{dL}$, which was only performed in 36 patients identified $83 \%$ correctly.

\section{Analysis of the Exudative Effusion}

In the present study, Light's criteria proved to have $100 \%$ sensitivity for exudates with a PPV for exudates reaching $88.30 \%$. On the other hand, clinical criteria and SAPA proved to have less sensitivity, i.e. $97.5 \%$ for exudates. In the Santiago Romera et al study [1986-1989], the sensitivity for exudates by Light's criteria is $98 \%{ }^{1}$ It is the only study which examined the usefulness of clinical judgement alone and its added value to biochemical criteria. In their study, clinical criteria had a sensitivity of $94 \%$ for exudates. It is because 4 exudative effusions, due to trapped lung caused by TB and atelectasis due to lung cancer were wrongly classified as transudates. The exudative effusions in their study were caused by Pneumonia and Breast cancer. But in the present study, none of the exudates was misclassified by Light's criteria.

Since the size of the study group is small future studies with a large group are required, so that better clinical criteria can be evolved for more perfect separation of transudates and exudates, so that unnecessary expenditure and morbidity 
associated with thoracentesis can be avoided. It is also suggested that thoracentesis is not indicated in patients with CHF, Cirrhosis etc., on routine clinical practice and treatment of the systemic condition will resolve the effusion in most cases.

\section{CONCLUSION}

The results in the present study suggest that using clinical criteria, pleural effusions can be classified satisfactorily and in case of transudative effusions, there is no need of thoracentesis. So, in primary health centres where biochemical analysis is not available, clinical criteria can be used to identify transudates and exudates. The management can be directed towards underlying systemic condition and cost and morbidity associated with thoracentesis can be avoided as well.

\section{REFERENCES}

[1] Romero S, Candela A, Martin C, et al. Evaluation of different criteria for the separation of pleural transudates from exudate. Chest 1993;104 (2):399404.
[2] Romero-Candeira S, Hernández L, Romero-Brufao S, et al. Is It Meaningful to use biochemical parameters to discriminate between transudative and exudative pleural effusions? Chest 2002;122(5):1524-9.

[3] Roth BJ, O'Meara TF, Cragun WH. The serum-effusion albumin gradient in the evaluation of pleural effusions. Chest 1990;98(3):546-9.

[4] Dhar MC, Chaudhuri S, Basu K, et al. Significance of serum-effusion albumin-gradient in the differential diagnosis of pleural effusion. Ind J Tub 2000;47:229.

[5] Burgess LJ, Maritz FJ, Taljaard JJ. Comparative analysis of the biochemical parameters used to distinguish between pleural transudates and exudates. Chest 1995;107(6):1604-9.

[6] Bielsa S, Porcel JM, Castellote J, et al. Solving the light's criteria misclassification rate of cardiac and hepatic transudates. Respirology 2012;17(4):721-6.

[7] Dantu P, Pusuluri S. Diagnostic value of serum-effusion albumin gradient in the differential diagnosis of pleural effusion. Indian Journal of Health Sciences and Research 2012;1(2):30-5. 